The ability model of emotional intelligence: Searching for valid measures

\author{
Marina Fiori \\ marina.fiori@unil.ch \\ Institute of Psychology \\ Department of Organizational Behavior \\ University of Lausanne, Anthropole 3131.1 \\ CH-1015 Lausanne, Switzerland \\ John Antonakis \\ john.antonakis@unil.ch \\ Department of Organizational Behavior \\ Faculty of Business and Economics \\ University of Lausanne, Internef 618 \\ 1015 Lausanne, Switzerland
}

"In press"

Personality and Individual Differences 


\section{The ability model of emotional intelligence: Searching for valid measures}

Current measures of ability emotional intelligence (EI)—in particular the well-known MayerSalovey-Caruso Emotional Intelligence Test (MSCEIT)--suffer from several limitations, including low discriminant validity and questionable construct and incremental validity. We show that the MSCEIT is largely predicted by personality dimensions, general intelligence, and demographics having multiple R's with the MSCEIT branches up to .66; for the general EI factor this relation was even stronger (Multiple $\mathrm{R}=.76$ ). As concerns the factor structure of the MSCEIT, we found support for four first-order factors, which had differential relations with personality, but no support for a higher-order global EI factor. We discuss implications for employing the MSCEIT, including (a) using the single branches scores rather than the total score, (b) always controlling for personality and general intelligence to ensure unbiased parameter estimates in the EI factors, and (c) correcting for measurement error. Failure to account for these methodological aspects may severely compromise predictive validity testing. We also discuss avenues for the improvement of ability-based tests.

Keywords: emotional intelligence; MSCEIT; ability; general intelligence; personality; measurement error; psychometrics; validity. 


\section{Introduction}

Skeptics and supporters debating on the importance of Emotional Intelligence (EI) have different opinions about which stream, the trait or ability approach, may hold most promise (e.g., Antonakis, Ashkanasy \& Dasborough, 2009; Fiori, 2009; Petrides, Furnham, \& Frederickson, 2004; Matthews, Zeidner \& Roberts, 2004; Saklofske, Austin, \& Minski, 2003). Whereas several self-report questionnaires have been developed to measure EI as a trait, there is a paucity of tests that attempt to gauge EI as an ability. The only established standardized test is the Mayer Salovey Caruso Emotional Intelligence Test or MSCEIT (Mayer, Salovey, \& Caruso, 2002). Given the prominence of this test, whose validity may reflect on the EI ability movement as a whole, we closely analyzed its psychometric properties by examining its factor structure and focusing particularly on its relationship with personality and intelligence.

\section{In search of the elusive EI ability measure}

The first test introduced to measure EI as an ability was called the Multibranch Emotional Intelligence Scale (MEIS; Mayer, Salovey \& Caruso, 1997). This attempt was the first to measure EI according to objective performance rather than relying on self-reports; correct answers were scored in relation to the answer provided by the majority of respondents or alternatively by a pool of experts. A newer version of this test, the Mayer-Salovey-Caruso Emotional Intelligence Test (MSCEIT, Mayer et al., 2002) was developed to improve the construct validity of the MEIS. The test measures four branches of EI--emotion perception, using emotions to facilitate thought, emotion understanding, and emotion management--and employs two scoring systems, general and expert consensus, which correlate highly (from .93 to .99). Although developed to be more psychometrically sound than the MEIS, the MSCEIT showed high unreliability in its measures, as demonstrated by Føllesdal and Hagtvet (2009) who conducted a comprehensive analysis to estimate variance components associated with each 
branch and their generalizability coefficients. Keele and Bell (2008) also found problems with the reliability of the test and weak support for the theoretical model proposed by Mayer et al. (1997). Palmer et al. (2005) observed lower reliability coefficients for certain subscales and found partial support for the 4-factor structure.

As concerns the factorial structure of the MSCEIT, there is much controversy; Mayer, Salovey, Caruso and their colleagues find support for their theorizing (Mayer et al. 1999; Mayer, Salovey, Caruso, \& Sitarenios, 2003); however, others find conflicting results (Gignac, 2005; Keele and Bell, 2008; Palmer et al. 2005; Rossen, Kranzler, \& Algina, 2008). The issue of whether an underlying higher-order latent global EI factor--which was theorized by Mayer et al. (1999)--explains the variance in the four first order factors is rather contentious. Palmer et al. (2005) found partial support for a model with a general EI factor, whereas Rossen et al. (2008) found that a hierarchical model based on the theory behind the MSCEIT was an improper fit to the data. Gignac (2005) found that only the four-factor model had good fit whereas Keele and Bell (2008) found support for a three-factor solution. Still on a more fundamental level, researchers also question the convergent validity of the MSCEIT. For example, the perceiving branch does not correlate with established measures of emotion perception (Austin, 2010; Farrelly \& Austin, 2007; Roberts, Zeidner, \& Matthews, 2006).

As concerns the intercorrelations among the branches they are quite low, from .30 to .54 (Mayer et al., 2002), thus posing doubts about the presence of an underlying higher-order EI factor. Yet, Mayer, et al. (2003) claimed that an index of general EI should be considered rather than the individual branches (see also Mayer's, 2010 website). Consequently, most research published using the MSCEIT reports the total score rather than the single branches and draws conclusions accordingly. Thus, it seems of primary importance to understand whether a single score is the right measure to consider. 


\section{Does the MSCEIT measure something different from IQ and personality?}

Knowing whether EI is distinct from $g$ and personality is of primary importance. If the MSCEIT strongly correlates with these constructs then it is imperative that any research efforts using the MSCEIT factors as independent variables control for personality and general intelligence. If not, the effects of EI might be overstated and the coefficient of the EI factors will be confounded with the effects of the variables with which it is correlated (Antonakis, Bendahan, Jacquart, \& Lalive, in press). Besides the problem of including important controls, measurement error must be appropriately modeled given that EI, personality, and intelligence are psychological constructs that are imperfectly measured (Antonakis et al., in press). The assumption of predictive models is that independent variables are measured without error; if there is error, then it is important to account for this error in regression or structural equation models (Bollen, 1989). Failure to model this measurement error will lead to attenuated estimates for the variables measured with error as well and biased estimates for correlated control variables.

Several studies (e.g., Day \& Carroll, 2004; Roberts et al., 2006; Rode et al., 2008) tested the claim that EI is distinct from general intelligence and personality (Mayer, Caruso, \& Salovey, 1999). In particular, Schulte and colleagues (2004) conducted the analysis correcting for measurement error. The regression of EI scores on general intelligence measured by the Wonderlic Personnel Test, agreeableness measured by the NEO-PI (Costa \& McCrea, 1992) and sex yielded a multiple $R$ of .81, demonstrating a very strong relationship of these variables with EI. Such results cast serious doubt about the discriminant validity of the MSCEIT EI model.

We sought to replicate Schulte et al. study (2004) regarding the relationship between EI, personality, and general intelligence. In addition, we tested the claim that the MSCEIT measures an overarching construct of EI. In order to provide accurate results on the discriminant validity of the MSCEIT, we accounted for measurement errors in the independent variables. We also 
conducted analyses on the four branches to provide more comprehensive results.

\section{Method}

\section{Participants and procedure}

We recruited 149 participants from a large Midwest U.S. university subject pool. They completed paper-and-pencil questionnaires of intelligence, personality and an on-line version of the MSCEIT (administered previously). Splitting measurement occasions mitigates problems associated with common methods variance, in this case between personality and intelligence with EI (Antonakis et al., in press).

\section{Measures}

Mayer Salovey Caruso Emotional Intelligence Test (MSCEIT): This performance-based measure of EI (Mayer, Salovey, \& Caruso, 2002) assesses four dimensions (i.e., branches) of EI, using 141 items. These dimensions, each measured by two facets:

1. Perceiving Emotions (Branch 1): Identifying emotions conveyed through expressions (Scale A: Faces) and abstract pictures (Scale E: Pictures);

2. Facilitating Thought (Branch 2): How certain moods may facilitate thinking (Scale B: Facilitation) and comparison of emotions to sensations, such as color, light, and temperature (Scale F: Sensations);

3. Understanding Emotions (Branch 3): Connecting emotions to certain situations (Scale G: Blends) and knowledge of how emotions may change and develop (Scale C: Changes);

4. Managing Emotions (Branch 4): Rating which emotional strategy would be most appropriate to handle a situation (Scale H: Emotional Relations) and be effective for selfregulation (Scale D: Emotional Management).

Personality: We used the Big Five Inventory (BFI; John \& Srivastava, 1999) to measure extraversion, neuroticism, agreeableness, conscientiousness, and openness to experience. We 
used the short version (BFI-44, Benet-Martinez \& John, 1998), which includes 44 items on a 5point scale. Benet-Martinez and John (1998) reported alpha coefficients of $.88, .84, .79, .82$, and .81 , respectively, for the aforementioned dimensions.

General Intelligence Test: We used Cattell's “Culture Fair” test, Scale 3 Form B (Cattell, Krug, \& Burton, 1973). The scale includes four subtests involving different tasks: Completing series, classifying, solving matrices, and evaluating conditions. This scale's reliability is .85 .

\section{Results}

We estimated the models using a maximum likelihood estimator with robust variance estimates and a robust chi-square test (MPLUS 6.0, Muthén \& Muthén, 2010); we also controlled for age, sex, and ethnicity in all predictive specifications. Raw scores of the MSCEIT were used and they were scored by the test publishers according to experts' ratings. Refer to Table 1 for descriptive statistics and correlations.

[Insert Table 1 here]

\section{Confirmatory Factor Analysis of the MSCEIT V 2.0}

We conducted a CFA to test the 4-factor model of the MSCEIT constraining the two scales of each scale to load on their respective branch. We first ensured that the estimator was well approximated for this model and data using the Monte Carlo procedures recommended by Muthén and Muthén (2002). We also estimated a MIMIC (multiple indicator, multiple cause model) model, regressing the factors on the demographic variables so as to control for sample heterogeneity (Muthén, 1989).

The basic CFA model had excellent fit: $\chi^{2}(14)=16.24, p>.10$, RMSEA $=.03$, and CFI $=$ 99. However, the strength of the loadings (mean $\lambda=.73$ ) showed large differences for the branches: (a) Branch 1: Scales A $(\lambda=.92)$ and E $(\lambda=.41)$, (a) Branch 2: Scales B $(\lambda=.61)$ and F 
$(\lambda=.76)$, (a) Branch 3: Scales C $(\lambda=.94)$ and G $(\lambda=.62)$, (a) Branch 4: Scales D $(\lambda=.76)$ and $\mathrm{H}(\lambda=.83)$. The average latent correlation between the four factors was not very strong, $\Phi=.46$. Consequently, when we constrained the four branches to load on a higher-order factor the model failed to fit the data: $\chi^{2}(16)=39.78, p<.05$, RMSEA $=.10$, and CFI $=.91$, and the solution was also improper. The MIMIC models did not change the substantive findings. To further examine the differential loading issue, we also re-estimated the basic CFA model modeling tau-equivalent subscales (constraining the loadings of each of the branch indicators to equality); however, this model failed to fit the data: $\left.\chi^{2}(18)=55.55, p<.05\right)$, RMSEA $=.12$, and CFI $=.86$, suggesting that the subscales are not affected by the common factor in the same way.

\section{Discriminant Validity}

We simultaneously regressed the four EI branches on personality and general intelligence thus estimating an efficient MANOVA-type model (i.e., where the disturbances of the branches covary). We also regressed a higher-order EI factor indicated by the four branches on the controls for comparative purposes. To correct for measurement error in the independent variables, we created latent variables by constraining the residual variance of each independent variable $x$ to (1reliability $\left._{x}\right) *$ Variance $_{x}($ Bollen, 1989) using the population reliabilities. We estimated hierarchical SEM models by first entering the demographic variables, then the big five personality factors, and finally general intelligence. Furthermore, we compared coefficients when measurement error was not taken into account to show how much it may affect results (Table 2).

[Insert Table 2 here]

Our results replicate those of Schulte and colleagues (2004): Both general intelligence and personality predicted a substantial amount of variance in EI scales (with full multiple $R$ 's ranging from.49 to .76 , or respectively R-Squares of .24 to .58). Our results highlight differential effects 
of the control variables on the branches and with respect to the total EI score (which would be masked at the level of a general EI score). For instance, extraversion is unrelated to the overall score, negatively related to Branch 3 and positively related to Branch 4. Neuroticism also had differential effects. Furthermore, the personality dimensions were significantly predictive of the branches even after having entered general intelligence into the equation, with agreeableness having particularly high effects on Branches 2 and 4. General intelligence predicted three of four branches (and the total score) and the personality dimensions still remained predictive after intelligence was entered in the model. Also, as expected, coefficients of variables for which measurement error was not accounted for were attenuated (at times severely).

\section{Discussion}

Some have concluded that self-report measures of EI load more heavily on personality whereas ability measures on intelligence (Davies et al., 1998; Matthews et al., 2004). Our results showed that the MSCEIT is accounted for not only by general intelligence, but also largely by personality (cf. Schulte et al., 2004). Results differed among branches and with respect to the total EI score. Our results add to growing research showing limitations of ability-type EI measures (e.g., Antonakis \& Dietz, in press; Amelang \& Steinmayr, 2006; Føllesdal \& Hagtvet, 2009; Keele \& Bell, 2008; Palmer et al., 2005; Rode et al., 2008; Rossen et al. 2008; Schulte, Ree, \& Carreta, 2004).

Even though we used different personality and general intelligence tests, our results are similar to those obtained by Schulte et al. (2004), which we extended by showing the predictive contribution of personality and intelligence to each branch. Thus, scores for each branch should be considered separately, rather than a single global EI score, as also corroborated by our CFAs, which showed that the branches are largely distinct.

Finally, our results show the importance of accounting for measurement error: Model 
coefficients with and without measurement error correction indicate that coefficients can be substantially biased. For example, in the case of agreeableness predicting Branch 4 , the partial standardized coefficient when modeling measurement error $(\beta=.56)$ was $75 \%$ higher than when measurement error was not modeled (i.e., $\beta=.32$ ).

\section{Measuring EI as an Ability: In Search of Alternative Tests}

The principal aim of our study was to assess the psychometric properties of the MSCEIT. Our results confirmed that the MSCEIT overlaps substantially with personality and general intelligence, thus potentially offering quite low discriminant validity. To further substantiate these findings, it would be advisable to follow up this study with research examining the contribution of EI as a predictor of behavioral outcomes when personality and general intelligence are taken into account and, importantly, correcting for measurement error (cf. Antonakis \& Dietz, in press). Finally, researchers are advised to use the single branch scores rather than a global EI score.

A practical problem that researchers willing to study EI as an ability are confronted with is that there are basically no alternatives to the MSCEIT. Some attempts have been undertaken, such as the Situational Test of Emotional Understanding (STEM) and Situational Test of Emotion Management (MacCann \& Roberts, 2008), and others. However, few data are available about their psychometric properties and tests of reliability and discriminant validity are not very encouraging (Austin, 2010; MacCann, 2010); also, test items are very similar to those of the MSCEIT, offering more a replication than an alternative.

One way to overcome this measurement impasse is to improve the MSCEIT subscales so as to make the branches more homogenous. Another aspect worth considering would be regarding the scoring options. For instance the MSCEIT reports a correlation between expert and consensus ratings as high as .99 (Mayer, Salovey, \& Caruso, 2002). Such as correlation seriously 
challenges the logic behind the scoring strategy. In fact, it turns out that experts respond to MSCEIT items just like the majority of people. Thus, do emotion experts really exist? Rather than doubting the existence of experts in emotions, it seems more likely that the test does not discriminate among high and low emotionally skilled individuals. Imagine the case of IQ tests, where gifted individuals provide the same responses as do the majority of respondents: Such a finding would suggest that the test cannot sort high from average IQ individuals.

A strategy to adopt for changing or improving current scales might be to find items in which the difference between expert and general consensus is larger, rather than smaller (and hence offer more variability in individuals' scores). As it is scored now, the criterion of correctness reflects the highest percentage of people who chose the same answer, suggesting that the item is relatively easy. Thus, it seems to us that higher scores simply reflect performing well on easy items, which implies that the MSCEIT may not be identifying individuals highly skilled in reasoning with emotions, but simply those who got most of the easier items right.

We think that fundamentally new ways to measure EI are needed, focusing for instance on uncovering procedural rather than declarative emotion knowledge; this could be accomplished by analyzing how individuals react in real and emotionally-charged situation. Such "maximum" performance contexts have been shown useful in personnel selection (cf. Waldman \& Korbar, 2004). Alternatives might be found in a process-oriented approach to EI by identifying differences in emotion processes that may be responsible for how individuals actually manage emotions (cf. Fiori, 2009). Laboratory tasks that require processing of emotional information, such as those involving priming or managing different emotional information at the same time, may be useful (e.g., Austin, 2005; Farrelly \& Austin 2007). Individual differences in performance on the laboratory task, such as reaction time and/or speed of processing, would be used as predictors of how the person reacts in situations that require being able to manage emotions 
(Fiori, 2010).

\section{Conclusion}

Our critical evaluation of the MSCEIT using strong psychometric tests has highlighted major limitations of the most widely used ability test of EI in circulation; we have also made what we deem to be reasonable suggestions regarding how the MSCEIT should best be used in predictive studies. We hope that our contribution will encourage the scientific community to develop alternative ways to measure EI as an ability or to significantly improve current measures. 


\section{References}

Amelang, M., \& Steinmayr, R. (2006). Is there a validity increment for tests of emotional intelligence in explaining the variance of performance criteria? Intelligence, 34(5), 459468.

Antonakis, J., Ashkanasy, N. M., \& Dasborough, M. T. (2009). Does leadership need emotional intelligence? The Leadership Quarterly, 20, 247-261.

Antonakis, J., Bendahan, S., Jacquart, P., \& Lalive, R. (in press). On making causal claims: A review and recommendations. The Leadership Quarterly.

Antonakis, J., \& Dietz, J. (in press). Looking for Validity or Testing It? The Perils of Stepwise Regression, Extreme-Scores Analysis, Heteroscedasticity, and Measurement Error. Personality and Individual Differences.

Austin, E. J. (2005). Emotional intelligence and emotional information-processing. Personality and Individual Differences, 39,403-414.

Austin, E. J. (2010). Measurement of ability emotional intelligence: Results for two new tests. British Journal of Psychology, 101, 563-578.

Benet-Martinez, V., \& John, O. P. (1998). «Los Cinco Grandes » across cultures and ethnic groups: Multitrait- multimethod analyses of the Big Five in Spanish and English. Journal of Personality and Social Psychology, 75, 729-750.

Bollen, K. A. (1989). Structural equations with latent variables. New York: John Wiley \& Sons.

Cattell, R.B., Krug, S.E., \& Barton, K. (1973). Technical Supplement for the Culture Fair Intelligence Tests, Scales 2 and 3. Champaign: Institute for Personality and Ability Testing.

Costa, P. T., Jr., \& McCrae, R. R. (1992). Revised NEO Personality Inventory: Professional manual. Odessa, FL: Psychological Assessment Resources. 
Davies, M., Stankov, L., \& Roberts, R. D. (1998). Emotional Intelligence: In Search of an Elusive Construct. Journal of Personality and Social Psychology, 75, 989-1015.

Day. A. L., \& Carroll, S. A. (2004). Using an ability-based measure of emotional intelligence to predict individual performance, group performance, and group citizenship behaviours, Personality and Individual Differences, 36, 1443-1458.

Dempster, A. P., Laird, N. M., \& Rubin, D. B. (1977). Maximum Likelihood from Incomplete Data via the EM Algorithm. Journal of the Royal Statistical Society, 39, 1-38.

Farrelly, D., \& Austin, E. J. (2007). Ability El as an intelligence? Associations of the MSCEIT with performance on emotion processing and social tasks and with cognitive ability. Cognition \& Emotion, 21, 1043-1063.

Fiori, M. (2009). A new look at emotional intelligence: a dual-process framework. Personality and Social Psychology Review, 13, 1, 21-44.

Fiori, M. (2010). May The Force be with you: on activation and inhibition of anger, and the vicissitudes of emotion regulation. Manuscript submitted for publication.

Føllesdal, H., \& Hagtvet, K. A. (2009). Emotional intelligence: The MSCEIT from the perspective of generalizability theory. Intelligence, 37, 94-105.

Gignac, G. E. (2005). Evaluating the MSCEIT V2.0 via CFA: Comment on Mayer et al. (2003). Emotion, 5, 233-235.

John, O. P., \& Srivastava, S. (1999). The Big Five trait taxonomy: History, measurement, and theoretical perspectives. In L. A. Pervin \& O. P. John (Eds.), Handbook of personality: Theory and research (2nd ed., pp. 102-138). New York: Guilford.

Keele S. M., \& Bell R. C. (2008). The factorial validity of emotional intelligence: An unresolved issue. Personality \& Individual Differences, 44, 487-500.

MacCann, C. (2010). Further examination of emotional intelligence as standard intelligence: A 
latent variable analysis of fluid intelligence, crystallised intelligence, and emotional intelligence. Personality and Individual Differences, 49, 490-496.

MacCann, C., \& Roberts, R. D. (2008). New paradigms for assessing emotional intelligence: Theory and data. Emotion, 8, 540-551.

Matthews, G., Zeidner, M., \& Robert, R. (2004). Emotional Intelligence: Science and Myth. Cambridge: MIT.

Mayer, J. D. (2007). Emotional Intelligence Information. [WWW document]. URL http://www.unh.edu/emotional_intelligence/ei\%20Measuring\%20EI/ eiMeasure\%20what\%20are\%20there.htm. Retrieved July 21, 2010.

Mayer, J. D., Caruso, D., \& Salovey, P. (1999). Emotional intelligence meets traditional standards for an intelligence. Intelligence, 27, 267-298.

Mayer, J. D. \& Salovey, P. (1997). What is emotional intelligence? In P. Salovey \& D. Sluyter (Eds). Emotional development and emotional intelligence: Implications for educators (pp. 3-31). New York: Basic Books.

Mayer, J. D., Salovey, P., \& Caruso, D. (1997). Emotional IQ test (CD ROM). Needham, MA: Virtual Knowledge.

Mayer, J. D., Salovey, P., \& Caruso, D. R. (2002). Mayer-Salovey-Caruso Emotional Intelligence Test (MSCEIT). User's manual. Toronto, Canada: Multi-Health Systems. Mayer, J. D., Salovey, P., Caruso, D.R. \& Sitarenios, R. (2001). Emotional intelligence as a standard intelligence. Emotion, 1, 232-242.

Mayer, J. D., Salovey, P., Caruso, D. R., \& Sitarenios, G. (2003). Measuring emotional intelligence with the MSCEIT V2. 0. Emotion, 3, 97-105.

Muthén, B. O. (1989). Latent variable modeling in heterogenous populations. Psychometrika, 54, 557-585. 
Muthén, L. K., \& Muthén, B. O. (2002). How to use a Monte Carlo study to decide on sample size and determine power. Structural Equation Modeling, 9, 599-620.

Muthén, L. K., \& Muthén, B. O. (2010). Mplus user's guide (6th ed.). Los Angeles, CA: Muthén \& Muthén.

Palmer, B. R., Gignac, G., Manocha, R., \& Stough, C. (2005). A psychometric evaluation of the Mayer-Salovey-Caruso Emotional Intelligence Test Version 2.0. Intelligence, 33, 285305.

Petrides, K. V., Frederickson, N., \& Furnham, A. (2004). The role of trait emotional intelligence in academic performance and deviant behavior at school. Personality and Individual Differences, 36, 277-293.

Roberts, R. D., Schulze, R., O'Brien, K., MacCann, C., Reid, J., \& Maul, A. (2006). Exploring the validity of the Mayer-Salovey-Caruso Emotional Intelligence Test (MSCEIT) with established emotions measures. Emotion, 6, 663-669.

Roberts, R. D., Zeidner, M, \& Matthews, G. (2001). Does emotional intelligence meet traditional standards for an intelligence? Some new data and conclusions. Emotion, 1, 196-231.

Rode, J. C., Mooney, C. H., Arthaud-Day, M. L., Near, J. P., Rubin, R. S., Baldwin, T. T., et al. (2008). An examination of the structural, discriminant, nomological, and incremental predictive validity of the MSCEIT (c) V2.0. Intelligence, 36(4), 350-366.

Rossen, E., Kranzler, J. H., \& Algina, J. (2008). Confirmatory Factor Analysis of the MayerSalovey-Caruso Emotional Intelligence Test V2.0 (MSCEIT), Personality and Individual Differences 44, 1258-1269.

Saklofske, D. H., Austin, E. J., \& Minski, P. S. (2003). Factor structure and validity of a trait emotional intelligence measure. Personality and Individual Differences, 34, 707-721.

Schulte, M. J., Ree, M. J., \& Carretta, T. R. (2004). Emotional intelligence: Not much more than 
g and personality. Personality and Individual Differences, 37, 1059-1068.

Waldman, D. A., \& Korbar, T. (2004). Student Assessment Center Performance in the Prediction of Early Career Success. Academy of Management Learning \& Education, 3, 2, 151-167. 


\begin{tabular}{|c|c|c|c|c|c|c|c|c|c|c|c|c|c|c|c|c|c|c|c|c|c|c|}
\hline & & & 1 & 2 & 3 & 4 & 5 & 6 & 7 & 8 & 9 & 10 & 11 & 12 & 13 & 14 & 15 & 16 & 17 & 18 & 19 & 20 \\
\hline Variable & Mean & SD & & & & & & & & & & & & & & & & & & & & \\
\hline 1. B1 Perc. Emot. & .59 & .12 & .53 & & & & & & & & & & & & & & & & & & & \\
\hline 2. B2 Fac. Thght & .45 & .09 & .43 & .63 & & & & & & & & & & & & & & & & & & \\
\hline 3. B3 Und. Emot. & .56 & .12 & .28 & .38 & .73 & & & & & & & & & & & & & & & & & \\
\hline 4. B4 Mng. Emot. & .40 & .10 & .11 & .50 & .42 & .77 & & & & & & & & & & & & & & & & \\
\hline 5. EI Total & .50 & .07 & .67 & .77 & .75 & .68 & .66 & & & & & & & & & & & & & & & \\
\hline 6. Subscale A & .62 & .18 & .90 & .45 & .20 & .06 & .59 & - & & & & & & & & & & & & & & \\
\hline 7. Subscale B & .42 & .07 & .32 & .76 & .26 & .38 & .57 & .34 & - & & & & & & & & & & & & & \\
\hline 8. Subscale C & .60 & .13 & .28 & .45 & .88 & .43 & .72 & .22 & .32 & - & & & & & & & & & & & & \\
\hline 9. Subscale D & .39 & .09 & .07 & .40 & .39 & .85 & .57 & .02 & .34 & .39 & - & & & & & & & & & & & \\
\hline 10. Subscale E & .55 & .11 & .74 & .22 & .29 & .14 & .52 & .38 & .15 & .27 & .12 & - & & & & & & & & & & \\
\hline 11. Subscale F & .49 & .13 & .41 & .93 & .37 & .46 & .72 & .42 & .46 & .43 & .35 & .22 & - & & & & & & & & & \\
\hline 12. Subscale G & .52 & .14 & .22 & .23 & .89 & .33 & .61 & .15 & .15 & .58 & .31 & .24 & .23 & - & & & & & & & & \\
\hline 13. Subscale H & .41 & .14 & .12 & .49 & .38 & .94 & .64 & .08 & .35 & .38 & .63 & .13 & .46 & .29 & - & & & & & & & \\
\hline 14. Extraversion & 3.29 & .73 & -.01 & -.03 & -.22 & .14 & -.06 & -.02 & .07 & -.20 & .07 & -.01 & -.09 & -.20 & .16 & .83 & & & & & & \\
\hline 15. Agreeableness & 3.84 & .64 & .16 & .40 & -.10 & .18 & .20 & .22 & .28 & -.09 & .12 & -.02 & .39 & -.09 & .20 & .08 & .78 & & & & & \\
\hline 16. Consc. & 3.72 & .58 & .22 & .13 & -.03 & .10 & .15 & .20 & .08 & -.03 & .05 & .17 & .13 & -.02 & .12 & .07 & .29 & .75 & & & & \\
\hline 17. Neuroticism & 2.92 & .69 & -.25 & -.10 & -.01 & .09 & -.10 & -.25 & -.12 & -.01 & .08 & -.14 & -.07 & -.01 & .08 & -.25 & -.37 & -.15 & .76 & & & \\
\hline
\end{tabular}




\begin{tabular}{|c|c|c|c|c|c|c|c|c|c|c|c|c|c|c|c|c|c|c|c|c|c|c|}
\hline 18. Openness & 3.63 & .54 & .07 & .09 & .30 & .35 & .29 & .05 & .00 & .25 & .23 & .08 & .12 & .29 & .37 & .07 & -.12 & .14 & .13 & .72 & & \\
\hline 19. IQ & 22.48 & 4.80 & .37 & .29 & .31 & .01 & .36 & .39 & .47 & .31 & .03 & .19 & .13 & .24 & .00 & -.02 & .03 & -.14 & -.26 & -.10 & - & \\
\hline 20. Male & .43 & .50 & -.08 & -.23 & -.13 & -.26 & -.24 & -.01 & -.15 & -.12 & -.21 & -.17 & -.23 & -.12 & -.26 & .06 & -.11 & -.07 & -.24 & -.11 & .13 & - \\
\hline 21. Age & 19.12 & 1.81 & -.22 & -.15 & -.09 & .02 & -.16 & -.22 & -.19 & -.07 & .02 & -.12 & -.09 & -.09 & .01 & -.05 & -.26 & .06 & .12 & .07 & -.13 & .23 \\
\hline
\end{tabular}

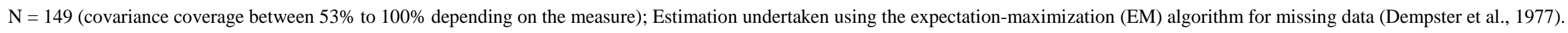
For $\mathrm{r}>|.16|, \mathrm{p}<.05 ; \mathrm{r}>|.21|, \mathrm{p}<.01 ; \mathrm{r}>|.27|, \mathrm{p}<.001$; Sex dummy coded (male = 1, female $=0$ ); reliabilities on diagonals. 
Table 2. Standardized effects of IQ, personality, and demographics on EI.

\begin{tabular}{|c|c|c|c|c|c|c|c|c|c|c|c|c|c|c|c|}
\hline \multirow[t]{2}{*}{ VARIABLES } & \multicolumn{3}{|c|}{$\begin{array}{c}\text { Perceiving } \\
\text { Emotions (Branch 1) }\end{array}$} & \multicolumn{3}{|c|}{$\begin{array}{c}\text { Facilitating } \\
\text { Thought (Branch 2) }\end{array}$} & \multicolumn{3}{|c|}{$\begin{array}{c}\text { Understanding } \\
\text { Emotions (Branch 3) }\end{array}$} & \multicolumn{3}{|c|}{$\begin{array}{c}\text { Regulating } \\
\text { Emotions (Branch 4) }\end{array}$} & \multicolumn{3}{|c|}{ Total EI } \\
\hline & Step 1 & Step 2 & Step 3 & Step 1 & Step 2 & Step 3 & Step 1 & Step 2 & Step 3 & Step 1 & Step 2 & Step 3 & Step 1 & Step 2 & Step 3 \\
\hline \multirow[t]{2}{*}{ Male $(=1 ;$ else 0$)$} & .00 & -.09 & -.06 & $-.18 \dagger$ & -.12 & $-.17 \dagger$ & -.12 & -.12 & -.12 & $-.27 *$ & -.13 & $-.19 *$ & $-.26 \dagger$ & -.19 & -.19 \\
\hline & & $(-.05)$ & $(-.05)$ & & $(-.16 \dagger)$ & $(-.16)$ & & $(-.10)$ & $(-.14)$ & & $(-.20 *)$ & $(-.21 *)$ & & $(-.24 \dagger)$ & $(-.24 *)$ \\
\hline \multirow[t]{2}{*}{ Age } & -.15 & -.15 & -.12 & -.22 & -.09 & -.10 & -.09 & -.13 & -.10 & .08 & .13 & .10 & -.18 & -.05 & -.05 \\
\hline & & $(-.14)$ & $(-.11)$ & & $(-.14)$ & $(-.09)$ & & $(-.13)$ & $(-.10)$ & & $(.10)$ & (.13) & & $(-.09)$ & $(-.07)$ \\
\hline \multirow[t]{2}{*}{ Race: Asian } & -.03 & .01 & .02 & -.13 &.-14 & -.09 & $-.34 * *$ & $-.30^{*}$ & $-.28 *$ & -.17 & $-.22 \dagger$ & -.19 & -.26 & $-.29 \dagger$ & -.21 \\
\hline & & $(-.01)$ & $(-.03)$ & & $(-.13)$ & $(-.13)$ & & $(-.32 * *)$ & $(-.27 *)$ & & $(.20 \dagger)$ & $(-.20)$ & & $(-.29 \dagger)$ & $(-.26)$ \\
\hline \multirow[t]{2}{*}{ Race: Afr.-Amer. } & .08 & .06 & .07 & .11 & -.07 & .03 & -.11 & $-.22 \dagger$ & $-.16 \dagger$ & .03 & -.19 & -.10 & .07 & -.20 & -.14 \\
\hline & & $(.05)$ & $(.09)$ & & $(.00)$ & $(.02)$ & & $(-.18 \dagger)$ & $(-.20 \dagger)$ & & $(-.09)$ & $(-.10)$ & & $(-.10)$ & $(-.09)$ \\
\hline \multirow[t]{2}{*}{ Race: Hispanic } & -.04 & .02 & .04 & -.07 & $-.27 \dagger$ & -.11 & -.12 & -.11 & -.03 & .06 & $-.30^{*}$ & -.16 & -.07 & $-.36^{*}$ & -.22 \\
\hline & & $(-.02)$ & $(.01)$ & & $(-.18)$ & $(-.15)$ & & $(-.10)$ & $(-.06)$ & & $(-.16)$ & $(-.17 \dagger)$ & & $(-.23 \dagger)$ & $(-.19)$ \\
\hline \multirow[t]{2}{*}{ Race: not indicated } & -.08 & -.02 & -.00 & -00 & -.12 & -.01 & $-.30 *$ & $-.30 * *$ & $-.24 *$ & -.02 & $-.20 \dagger$ & -.12 & -.10 & $-.28 \dagger$ & -.17 \\
\hline & & $(-.05)$ & $(-.05)$ & & $(-.06)$ & $(-.01)$ & & $(-.30 * *)$ & $(-.24 *)$ & & $(-.12)$ & $(-.13)$ & & $(-.20)$ & $(-.15)$ \\
\hline \multirow[t]{2}{*}{ Extraversion } & & -.16 & -.10 & & .01 & -.00 & & $-.35^{* *}$ & $-.28 * *$ & & $.29 \dagger$ & $.24 \dagger$ & & .02 & -.02 \\
\hline & & $(-.10)$ & $(-.05)$ & & $(.00)$ & $(.00)$ & & $(-.27 * *)$ & $\left(-.26^{* *}\right)$ & & $(.24 \dagger)$ & $\left(.26^{*}\right)$ & & $(.02)$ & $(-.02)$ \\
\hline \multirow[t]{2}{*}{ Agreeableness } & & -.19 & -.09 & & $.56^{* * *}$ & $.37 * *$ & & -.10 & -.10 & & $.57 * *$ & $.56^{* *}$ & & $.60^{*}$ & $.54^{*}$ \\
\hline & & $(-.07)$ & $(-.07)$ & & $(.37 * * *)$ & $\left(.36^{* * *}\right)$ & & $(-.08)$ & $(-.06)$ & & $(.32 * *)$ & $(.32 * *)$ & & $(.37 *)$ & $(.33 \dagger)$ \\
\hline Conscientiousness & & .22 & $.23^{*}$ & & -.15 & .01 & & -.07 & .03 & & -.14 & -.03 & & -.17 & -.03 \\
\hline
\end{tabular}




\begin{tabular}{|c|c|c|c|c|c|c|c|c|c|c|c|c|c|c|c|}
\hline \multirow{3}{*}{ Neuroticism } & & $(.17)$ & $(.17)$ & & $(-.05)$ & $(-.02)$ & & $(-.03)$ & $(.05)$ & & $(-.03)$ & $(-.03)$ & & $(-.04)$ & $(.02)$ \\
\hline & & $-.39 *$ & $-.22 *$ & & .09 & .08 & & -.24 & -.08 & & $.33^{*}$ & $.20 *$ & & .10 & .16 \\
\hline & & $(-.27 * *)$ & $(-.19 \dagger)$ & & $(.00)$ & $(.09)$ & & $(-.13)$ & $(-.06)$ & & $\left(.19^{*}\right)$ & $(.18 *)$ & & $(.02)$ & $(.07)$ \\
\hline \multirow[t]{2}{*}{ Openness } & & .08 & .08 & & .24 & .14 & & $.44 * * *$ & $.33 * * *$ & & $.47 * *$ & $.34 * *$ & & $.54^{*}$ & $.46 \dagger$ \\
\hline & & $(.08)$ & $(.10)$ & & $(.14)$ & $(.15)$ & & $(.33 * * *)$ & $(.34 * * *)$ & & $(.33 * * *)$ & $(.34 * *)$ & & $(.37 *)$ & $(.37 *)$ \\
\hline \multirow[t]{2}{*}{ General Intelligence } & & & $.25^{*}$ & & & $.30 * *$ & & & $.28^{*}$ & & & .04 & & & $.39 *$ \\
\hline & & & $\left(.26^{*}\right)$ & & & $(.30)^{* *}$ & & & $\left(.28^{*}\right)$ & & & $(.04)$ & & & $\left(.36^{* *}\right)$ \\
\hline \multirow[t]{2}{*}{ R-square } & .04 & $.18^{*}$ & $.24^{*}$ & $.14 \dagger$ & $.31 * *$ & $.39 * *$ & $.13 \dagger$ & $.35^{* * *}$ & $.42 * * *$ & $.12 \dagger$ & $.44 * * *$ & $.44 * * *$ & $.20 \dagger$ & $.51 * *$ & $.58 * *$ \\
\hline & & $(.13 *)$ & $\left(.18^{*}\right)$ & & $(.24 * *)$ & $(.32 * *)$ & & $(.28 * * *)$ & $(.35 * * *)$ & & $(.31 * * *)$ & $(.29 * *)$ & & $(.39 * *)$ & $\left(.48^{* * *}\right)$ \\
\hline \multirow[t]{2}{*}{ Multiple-R } & .19 & $.42 *$ & $.49^{*}$ & $.37 \dagger$ & $.55 * *$ & $.62 * *$ & $.36 \dagger$ & $.59 * * *$ & $.65 * * *$ & $.34 \dagger$ & $.66 * * *$ & $.66^{* * * *}$ & $.45 \dagger$ & $.71 * *$ & $.76^{* *}$ \\
\hline & & $\left(.36^{*}\right)$ & $(.42 *)$ & & $(.49 * *)$ & $(.57 * *)$ & & $(.53 * * *)$ & $(.59 * * *)$ & & $(.56 * * *)$ & $(.54 * *)$ & & $(.62 * *)$ & $(.69 * * *)$ \\
\hline Delta R-Square $^{1}$ & & $.14 \dagger$ & $.06 * * *$ & & $.17 *$ & $.08 * * *$ & & $.22 * *$ & $.07 * *$ & & $.32 * *$ & .00 & & $.31 * * *$ & $.07 * * *$ \\
\hline
\end{tabular}

$\mathrm{N}$-size $=149$ (estimation with EM Algorithm); standard errors are robust; $p$ values: $\dagger p<=.10 ; * p<=.05 ; * * p<=.01 ; * * * p<=.001$; in parentheses are results when measurement error was not modeled. Reference category for race is "White." Note, the model with EI as a higher order factor was rejected by the chi-square test of fit; results are reported for comparative purposes. ${ }^{1}$ For models with measurement error only (nested Satorra-Bentler scaled chi-square difference test for each Branch and for Total EI model conducted independently). 